\title{
Cross-border cooperation in teaching the coordinate metrology
}

\author{
Współpraca transgraniczna \\ w nauczaniu metrologii współrzędnościowej
}

\section{MIROSŁAW WOJTYŁA LENKA ČEPOVÁ FRANTIŠEK ŠPALEK *}

DOI: https://doi.org/10.17814/mechanik.2017.12.198

\begin{abstract}
VSB-Technical University of Ostrava, Faculty of Mechanical Engineering together with University of Bielsko-Biala, Laboratory of Metrology submitted a proposal of common education project in the framework of the Interreg V-A Czech Republic-Poland program entitled: "Increasing employment of graduates of technical universities in practice". The paper presents an outline for chosen laboratory classes based on the standards ISO 10360, VDI/VDE 2617 and ISO 230.

KEYWORDS: education, coordinate metrology, CMM programming
\end{abstract}

The project focuses on education, improving qualifications and improving the skills of university graduates. It will be implemented as part of training modules in the form of weekly trainings divided into lectures (theoretical classes), exercises (practical and measurement classes), trips and courses of the Polish and Czech language. Planned activities include transfer of knowledge about new, developing technologies, measurement methods and methods of their use in industrial practice.

The project will focus on increasing the employment opportunities of technical university graduates. It is addressed mainly to students of the last years of engineering, master's and doctoral studies in the field of machine building.

\section{The goal of the project}

The main goal of the project is to support and improve qualifications of graduates in the field of machine building (students of final years of engineering and master's studies, as well as doctoral students) through special educational activities.

Additional objectives arise from the main objectives of the project:

- improving the employment rate of graduates in the labor market and reducing unemployment among graduates in the mechanical engineering sector on the Czech-Polish border,

\footnotetext{
* $\mathrm{Dr}$ inż. Lenka Čepová, (lenka.cepova@vsb.cz), František Špalek (rantisek.spalek@vsb.cz) - VSB-Technical University of Ostrava, dr inż. Mirosław Wojtyła (mwojtyla@ath.bielsko.pl) Akademia Techniczno-Humanistyczna w Bielsku-Białej
}

- increasing the opportunities for cross-border employment of graduates and building qualitative relations between cooperating institutions on the CzechPolish border.

Cross-border cooperation and link with regional strategy

The project is eligible for the Interreg V-A Czech Republic-Poland program, which focuses on promoting cooperation between the Czech Republic and the Republic of Poland. The institution managing the program is the Ministry of Regional Development of the Czech Republic, Department of European Territorial Cooperation.

Project activities are part of the "Regional strategy of the Moravian-Silesian region for 2014-2020", which is in line with the new European Commission 2020 strategy and national development priorities in the Czech Republic and Poland for 2014-2020. Project activities are related to the RIS3 of the Moravian-Silesian region and the specific objective "B4 - increasing the number of technical graduates and identification of technical capabilities". The project is also part of the vision of development of the subregion described in the "Strategy for development of the southern Silesian sub-region for the years 2014-2020" by: - offering high quality education and social services,

- access to education adapted to the needs of the labor market,

- development of entrepreneurship in the sphere of research and development services,

- creative education trends corresponding to the challenges of modern economy,

- development of cross-border and transnational cooperation by public and private entities.

The participation of mainly future university graduates and representatives of the enterprise sector in the project will have a positive impact on the entire border region (Moravian-Silesian and Bielsko region).

Improving the skills and knowledge of project participants will contribute to increasing the employment of graduates in enterprises on both sides of the border. They will be able to use the skills of qualified young employees. The cooperation agreement between the two universities and planned activities show that the impact of the project will be balanced and will cover the target group on both sides of the border area. 


\section{Beneficiaries of the project}

The target group of the project are students of the last year of engineering studies and all years of master's and doctoral studies. Because the priority axis 3 focuses on education and skills, and its specific goal is to raise the employment level of graduates and students of the last year, universities are a typical place to look for project beneficiaries. As part of the project, it is planned to support a total of 436 students (graduates men and women) of technical faculties run by both partners. The distribution of persons supported under the individual actions will be as follows:

- Employment Meeting (EmM) - Meetings with Employers - a total of 120 people will participate in the activities (60 on the Czech side, 60 on the Polish side). The Employment Meeting will be implemented once at each partner;

- Education Week (EdW) - Education Week - 132 people will participate in the activities (66 on the Czech and Polish side). The Educational Week will be organized six times during the project; two teachers and 20 students will take part in each week;

- Laboratory Week (LbW) - Laboratory Week - 96 people will participate in the activities (48 on the Czech and Polish side). Laboratory Week will be held 16 times (eight each of each partner); Only one teacher and five students will participate in it. The number of participants is limited due to the maximum number of people who can stay in laboratory rooms;

- Excursion Week (ExW) - Cruise Week - 88 people will participate in the activities (44 on the Czech and Polish side). Excursion Week will be run twice by each partner (a total of four times); Only two teachers and 20 students will always participate in it.

\section{Implementation of the project}

The main activities under the project will be implemented during: EdW, LbW, ExW and EmM.

EdW will consist in lectures. Examples of planned lecture topics:

- CAM systems in processing,

- Measurements of geometrical deviations,

- Coordinate measurements,

- Control and measurement technology,

- Geometrical product specifications,

- Uncertainty of coordinate measurements,

- Coordinate measuring technique,

- CMM programming,

- Programming of CNC machine tools.

During LbW, beneficiaries will take part in monothematic practical training. Measurements will be made on modern devices, machines and devices that the project partners have at their disposal. LbW will be designed for small groups to ensure the best possible results. Sample topics:

- Measurements of surface roughness and topography (including surfaces with layered functional properties); 2D and 3D parameters; filters (cut-off),

- CMM programming (online and offline),

- Calibration of the coordinate measuring machine (Length measurement error E, probing head error P),

- Checking the accuracy of machine tools (laser interferometer, determination of positioning error, straightness error, perpendicularity error),
- Reverse engineering (measurement with a scanner, CAD model construction, proposition of geometry specification: choice of dimensioning and tolerance, choice of tolerance value, 3D printing),

- Coordinate measurements of free surfaces (using CMM Wenzel),

- Multi-axis machining (operation of the DMG MORI machine tool - lathes with driven tools, five-axis simultaneous milling),

- 3D tasks, rapid prototyping,

- Assembly,

- Water cutting (laser + water).

As part of the ExW week for Czech students, trips to Polish companies will be organized, which will be provided by the partner ATH Bielsko-Biała, and Polish students will visit Czech companies, which will be provided by the VŠBTUO partner. Students will concentrate on practical and technical aspects of the functioning of companies and institutions on the Czech-Polish border.

\section{Examples of laboratory exercises: checking the accuracy of machine tools}

The aim of the exercise is to learn the method of checking the accuracy of machine tools using a laser interferometer, determining the compensation table and implementing it on the machine tool.

The idea of compensating the spatial positioning error of the CNC machine due to its geometrical inaccuracies is presented in the article [3].

An example of checking the accuracy of machine tools is the determination of the accuracy and repeatability of positioning of numerically controlled axes according to [4].

In the case of using a laser interferometer, the devices determining the measurement base should be stably fixed on a selected part of the base. The movable element is attached to the tool holder and its center should be as close as possible to the active tool zone [1]. An example of mounting the HPI-3D interferometer (LASERTEX) on the TUG 56MN lathe (DEFUM) is shown in fig. 1.

It should be possible to measure the relative displacement between the part in which the tool is attached and the part in which the workpiece is attached. On the axes of travel up to $2000 \mathrm{~mm}$, at least five positions per meter and on the entire axis of at least five preset positions should be selected in accordance with formula (1).

$$
P_{i}=(i-1) \times p+r
$$

where: $i$ - number of the current set position, $p$ - base spacing of evenly spaced set points over the entire measurement travel, $r$ - assumes different values for each set position. 


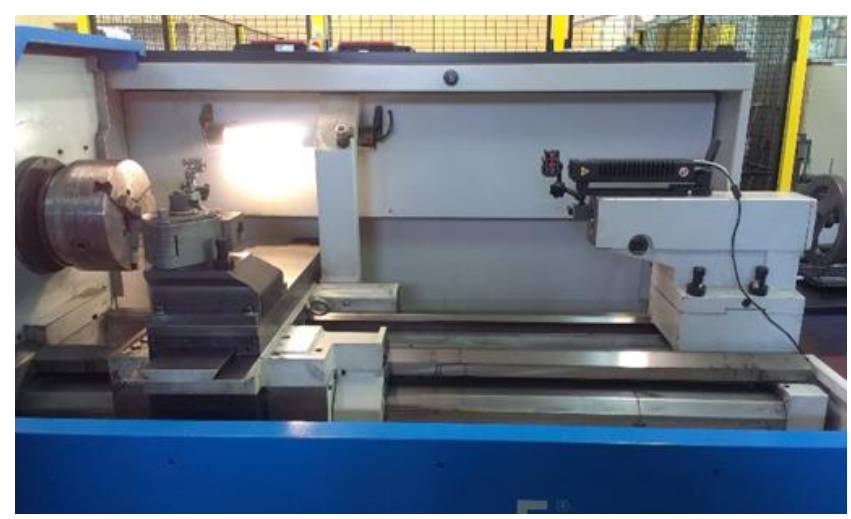

Fig. 1. Attaching the interferometer on the machine tool

The points should be arranged in such a way as to ensure that periodic errors, e.g. from the pitch of the ball screw, are properly taken into account. The measurements should be made in all set positions, according to the standard cycle, with each position being achieved five times in each direction $(n=5)$. The most common is the linear cycle.

After the measurement is completed, the parameters are evaluated, e.g.:

- A - two-way accuracy of axis positioning,

- $\mathbf{A} \uparrow ; \mathbf{A} \downarrow$ - one-way accuracy of axis positioning,

- E - bi-directional systematic deviation of axis positioning,

- $\mathbf{E} \uparrow ; \mathbf{E} \downarrow$ - one-way systematic deviation of axis positioning,

- $\mathbf{R}$ - bi-directional axis positioning repeatability,

- $\mathbf{R} \uparrow ; \mathbf{R} \downarrow$ - one-way repeatability of axis positioning,

- B - axial return value,

- B - average axial return value.

Software used in the laboratory interferometer to check machine tools allows, among others, for:

- generating the CNC code for a machine tool (compatible with the majority of control systems) - an example program code is shown in fig. 2 ,

- choice of measurement method (inter alia: linear, pendulum, pilgrim effective and pilgrim standard),

- generating points automatically or defining points from the list,

- generating a compensation table (fig. 3),

- generating a report with graphs (fig. 4) and comparison with limit values according to ISO, ASME, JIS standards.

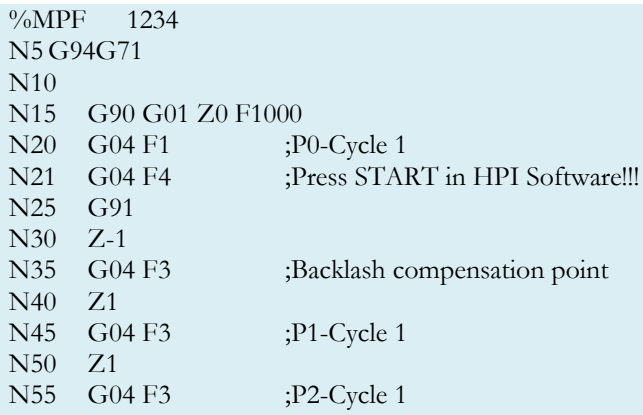

Fig. 2. Program in G-code

\section{$\%$ N_AX2_EEC_INI}

METRIC

CHANDATA(1)

N32450 \$MA_BACKLASH $[0$, AX2 $]=-0.0525$

N32700 \$MA_ENC_COMP_ENABLE[0,AX2] =1

\$AA_ENC_COMP_MIN $[0, \overline{A X} 2]=0.0000$

\$AA_ENC_COMP_MAX $[0, A X 2]=499.0000$

\$AA_ENC_COMP_STEP $[0, A X 2]=1.0000$

\$AA_ENC_COMP $[0,0, \mathrm{AX} 2]=0.0000$

\$AA_ENC_COMP $[0,1, \mathrm{AX} 2]=-0.0020$

\$AA_ENC_COMP $[0,2, \mathrm{AX} 2]=-0.0030$

$\$$ AA_ENC_COMP $[0,3, \mathrm{AX} 2]=-0.0040$

\$AA_ENC_COMP $[0,4, \mathrm{AX} 2]=-0.0050$

$\$ A A \_E N C \_C O M P[0,5, A X 2]=-0.0060$

Fig. 3. Compensation table

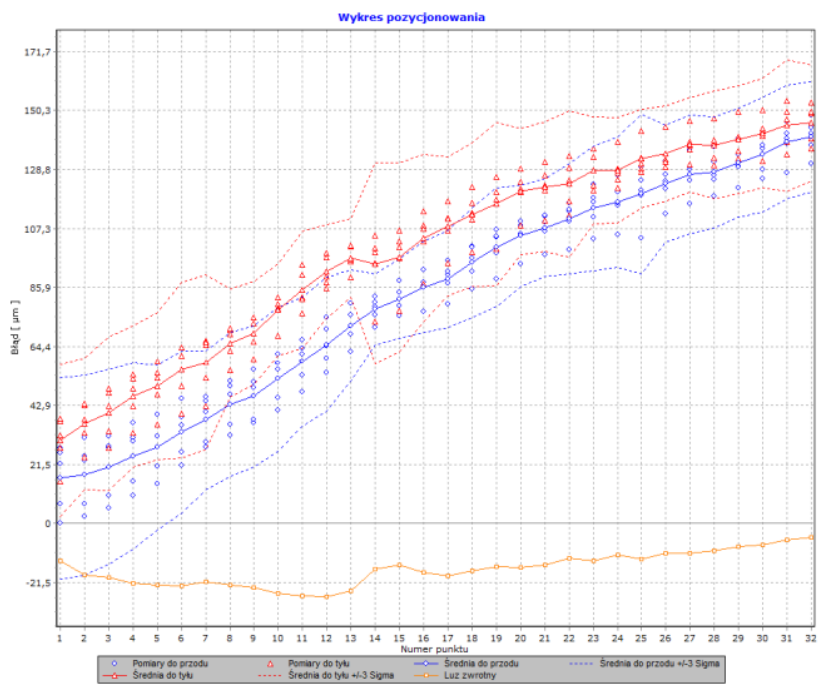

Fig. 4. Example of a measurement report

Fig. 4 shows machine tool errors for each cycle (both for forward and backward measurements), mean values of these errors and backlash

\section{Interim check CMM}

The aim of the exercise is to get acquainted with one of the methods of calibration of coordinate measuring machines and to determine errors of CMM indications.

The ball plate can be used to periodically check the CMM. Checking the CMM between inspection dates ensures the company is sure that its products are measured on a good machine. According to [5], there are two ways to set patterns:

- for one measuring cycle the ball plate is positioned vertically on the CMM table diagonal (about $30 \div 45^{\circ}$ in relation to one of the CMM axes),

- the ball plate is placed parallel to the measuring plane formed by the two CMM axes (one horizontal and two vertical); to improve interim checking of the entire CMM measuring space, the ball plate can be moved and measured in several positions.

Each of the 25 balls of a standard is measured at one point on the pole and in four pairs of opposite points near the sphere's equator. Measurements begin from ball 1 , then measure the balls: $2,3,4,5,10,9,8,7,6,11$ etc. up to ball 25. Then measure the balls $1,5,21$ again to detect the changes that can occur at the ball position during the measurement process. If the coordinates of the three ball centers differ more than the value of the factor $A$ in the formula for $E_{M P E}$, the current check should be stopped. 
After measuring all the balls, calculate the distances between the centers of all balls 1/2, 1/3 (a total of 300 distances for a plate with 25 balls). The distance $L$ between the two measured balls in position $i$ and $j$ of the ball plate pattern is calculated as:

$$
L_{i, j}=\sqrt{\left(x_{i}-x_{j}\right)^{2}+\left(y_{i}-y_{j}\right)^{2}+\left(z_{i}-z_{j}\right)^{2}}
$$

The absolute value of the ball center distance error $\Delta L$ - calculated as the difference between the measured distance $L$ ' between the balls and the reference distance $L$ - is calculated from the formula:

$$
\Delta L_{i, j}=L_{i, j}^{\prime}-L_{i, j}
$$

The absolute of the distance error cannot exceed the $E_{M P E}$ value. Fig. 5 shows the absolute error value of ball centers distance for one position of a ball plate.

The $I C$ factor is defined as the largest (max) value of the indicator calculated from the formula for all ball distances:

$$
I C=\left(\frac{|\Delta L|}{E_{M P E}}\right)_{M A X}
$$

The value of the $I C$ coefficient should be given to two decimal places. For the purpose of checking the stability, the $I C$ should be recorded on the control card. If any IC factor exceeds 1 , take steps to rectify the problem.

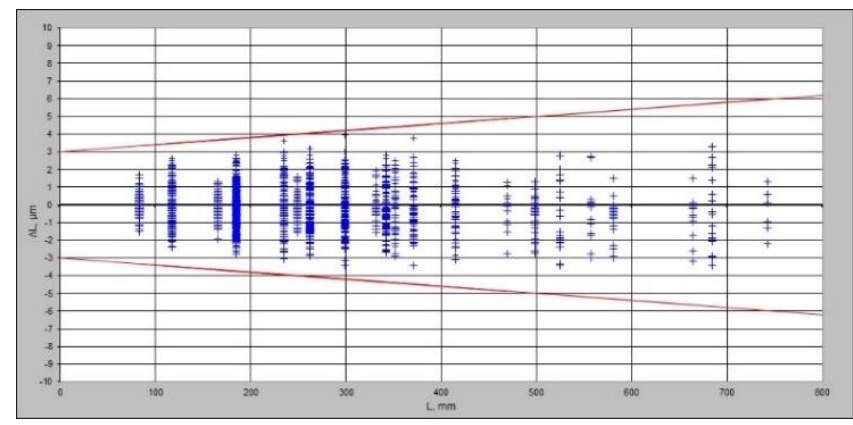

Fig. 5. CMM errors

\section{Conclusions}

The expected effect of the project is to increase the skills and knowledge of participants, which will allow graduates to find employment faster on the labor market both in the Czech Republic and in Poland. Transfer of knowledge about new, developing technologies, measurement methods and methods of their use in industrial practice will allow graduates and their future employers from border regions to use these technologies.

The proposed examples of laboratory exercises in the field of coordinate measuring technology will broaden the knowledge of beneficiaries obtained during the studies.

Periodic checking of CMM machine tools and machines is very important from the point of view of correct production, especially in times when the finished blank goes directly to the production line of another plant.

\section{REFERENCES}

1. ISO 230-1:1996 Test code for machine tools. Part 1: Geometric accuracy of machines operating under no-load or finishing conditions.

2. ISO 10360-2:2009 Geometrical product specifications (GPS). Acceptance and reverification tests for coordinate measuring machines (CMM). Part 2: CMMs used for measuring linear dimensions.

3. Majda P. "Geometric error measurement and compensation of machine tool CNC". Inżynieria Maszyn. 16, 1-2 (2011): s. $126-134$

4. ISO 230-2:1999 Test code for machine tools. Part 2: Determination of accuracy and repeatability of positioning numerically controlled axes.

5. VDI/VDE 2617 Part 5.1Accuracy of coordinate measuring machines. Parameters and their reverification Interim check with ball plates. January 2011.

6. Projekt „Zwiększenie zatrudnienia absolwentów wyższych uczelni technicznych w praktyce", nr rejestracyjny projektu: CZ.11.3.119/0.0/0.0/15_005/0000050 w ramach programu „Interreg V-A Republika Czeska - Polska”. 